\title{
SISTEM PENDUKUNG KEPUTUSAN MUTASI KARYAWAN PADA PT. SAKATO JAYA DENGAN METODE MULTI FAKTOR EVALUATION PROSES
}

\author{
ARMAN $^{1}$, ZAINUL EFENDY ${ }^{2}$, EDO SUGIARTO ${ }^{3}$ \\ Sistem Informasi, STMIK Indonesia Padang ${ }^{1,2,3}$ \\ Arman@ @stmikindonesia.ac.id ${ }^{1}$, Zainulefendy@stmikindonesia.ac.id ${ }^{2}$, Edo_sugiarto@ gmail.com ${ }^{3}$
}

\begin{abstract}
Proses pengambilan keputusan penyeleksian mutasi karyawan di PT. Bina Sakato Jaya Kiliran Jao saat ini masih dilakukan secara sederhana yaitu menggunakan Microsoft Office dalam penentuan karyawan yang dimutasi mempunyai faktor penilaian Disiplin, Prestasi kerja, dan Tanggung Jawab. Dalam pengambilan keputusan seleksi mutasi karyawan di instansi ini cukup lamban dan masih memakai aspek subjektif. Oleh Karena itu perlu dibuat sebuah aplikasi yang mampu menentukan seleksi mutasi karyawan yang optimal yang dapat membantu pimpinan instansi dalam mengambil keputusan yang lebih objektif. Untuk keputusan yang berpengaruh secara strategis, lebih dianjurkan menggunakan sebuah pendekatan kuantitatif seperti Multifactor Evaluation Process (MFEP). Dalam pengambilan keputusan dengan multifaktor, pengambilan keputusan secara subyektif dan intuitif dapat dihindarkan.
\end{abstract}

\section{Kata Kunci : Pengambilan keputusan, penerimaan calon Tenaga Honorer, Multifactor Evaluation Process.}

\section{PENDAHULUAN}

Kata Mutasi mungkin sudah terdengar tidak aneh di telinga para karyawan yang bekerja di Sebuah Perusahaan/Instansi Pemerintah. Perpindahan pegawai terjadi dalam setiap organisasi baik lembaga pemerintahan maupun organisasi perusahaan. Ada berbagai istilah perpindahan yang digunakan setiap organisasi, istilah yang umum digunakan adalah mutasi. Seperti Pelaksanaan Mutasi karyawan pada PT. Sakato Jaya. "Istilah-istilah yang sama pengertiannya dengan mutasi adalah pemindahan, alih tugas, transfer dan job rotation karyawan"[1]. Mengutarakan mutasi dengan istilah transfer: Transfer adalah perpindahan seorang karyawan dari satu pekerjaan ke posisi lainnya yang gaji, tanggung jawab dan/atau jenjang organisasionalnya sama..

Mutasi atau transfer adalah perpindahan pekerjaan seseorang dalam suatu organisasi yang memiliki tingkat level yang sama dari posisi pekerjaan sebelum mengalami pindah kerja. Kompensasi gaji, tugas dan tanggung jawab yang baru umumnya adalah sama seperti sedia kala. Mutasi atau rotasi kerja dilakukan untuk menghindari kejenuhan karyawan atau pegawai pada rutinitas pekerjaan yang terkadang membosankan dan juga disebabkan berbagai faktor. Seperti konfik kerja, tres kerja, Masalah stres dalam perusahaan menjadi gejala yang penting sejak mulai timbulnya tuntutan efisiensi dalam menyelesaikan suatu pekerjaan.

Salah satu faktor yang menyebabkan karyawan dimutasi sesebabkan oleh Stres. Menurut Davis dan Newstrom [2], menyatakan bahwa stres kerja disebabkan oleh beberapa kondisi sebagai berikut:

1. Adanya tugas yang terlalu banyak. Banyaknya tugas tidak selalu menjadi penyebab stres, tetapi akan menjadi sumber stres bila banyaknya tugas tidak sebanding dengan kemampuan baik fisik maupun keahlian dan waktu yang tersedia bagi karyawan.

2. Supervisor yang kurang pandai. Seorang karyawan dalam menjalankan tugas sehariharinya biasanya di bawah bimbingan sekaligus mempertanggungjawabkan kepada supervisor.

3. Terbatasnya waktu dalam mengerjakan pekerjaan. Karyawan biasanya mempunyai kemampuan normal menyelesaikan tugas kantor/perusahaan yang dibebankan kepadanya. Kemampuan berkaitan dengan keahlian, pengalaman, dan waktu yang dimiliki.

4. Kurang mendapat tanggungjawab yang memadai. Faktor ini berkaitan dengan hak dan kewajiban karyawan.

5. Ambiguitas peran. Agar menghasilkan performa yang baik, karyawan perlu 
mengetahui tujuan dan pekerjaan, apa yang diharapkan untuk dikerjakan

Pada PT. tersebut perusahaan. Mutasi ini dapat juga terkadang dijadikan sebagai tahapan awal atau batu loncatan untuk mendapatkan promosi di waktu mendatang.. penilaian mutasi karyawan masih dalam bentuk dokumentasi sederhana seperti Microsoft Office Word dan Microsoft office Excel dalam menentukan nilai akhir dari seluruh tahap tes dari seorang karyawan yang akan dimutasi sehingga informasi yang dihasilkan dalam penilaian mutasi karyawan tidak dapat dilaporkan secara tepat.

Penilaian tahapan tes dengan jumlah karyawan yang banyak akan menyulitkan pihak panitia dalam penilaian mutasi karyawan, sehingga hasil penilaian dan pertimbangan pengambilan keputusan cenderung biasa dan subjektif. Hal ini membuat pengambilan keputusan melakukan penilaian dan pertimbangan, sehingga cenderung terjadi kesalahpahaman dalam pengambilan keputusan mutasi karyawan yang sesuai dengan kriteria dari instansi secara maksimal.

Dengan adanya perkembangan TI ini sehingga data yang diperoleh pada PT. Bina Sakato Jaya Kiliran Jao proses pengambilan keputusan dengan metode (MFEP) dipandang layak untuk untuk memecahkan masalah yang ada pada PT. Bina Sakato Jaya Kiliran Jao, terutama dalam putusan mutasi kepada karyawan yang bekerja perusahaan tersebut dan juga dapat digunakan sebagai bahan pertimbangan dalam pengambilan keputusan yang tepat dan efisien.

\section{Identifikasi Masalah}

Berdasarkan pada hasil survei di PT. Bina Sakato Jaya Kiliran Jao, maka penulis dapat mengidentifikasi masalahnya yaitu sebagai berikut:

1. Banyaknya karyawan menyulitkan pihak panitia dalam menentukan karyawan yang akan dimutasi.

2. Informasi yang dihasilkan dalam keputusan mutasi karyawan tidak dapat dilaporkan secara tepat.

3. Data karyawan yang dimutasi belum tersimpan dalam bentuk database sehingga dalam pencarian data membutuhkan waktu yang lama.

\section{Tujuan Penelitian}

Adapun tujuan dari perancangan sistem yang sudah dirancanga yang baru, yang tidak terlepas dari kesempurnaan dari sistem yang lama di mana sistem yang baru sudah mengarah ke pada komputerisasi yang secara umum dapat diuraikan sebagai berikut :

1. Untuk mengetahu kelemahan dari sistem yang sedang berjalan, sehingga masalahan yang dihadapi selama ini dapat diatasi dengan baik.

2. Sistem yang dibangaun dirancangan sesui dengan keingin dari user, userfrenli efisien dan efektif dalam mengoperasikannya.

3. Untuk mengetahui manfaat dari sistem yang sudah dirancanga, dan dapat diimplementasikan pada perusahaan pt. Xx dengan baik.

4. Menganalisa kelemahan dari sistem yang lama yang nantinya akan dirancang sebuag sistem aplikasi yang baru yang dapat mengatasi kelemen-kelemnhan dari sistem yang lama dengan baik.

5. baru ini baru ini Tujuan dari penelitian pemberian keputusan mutasi karyawan ini adalah sebagai berikut:

6. Merancang SPK agar membantu pengambilan keputusan lebih efektif dan efisien dalam menyeleksi permutasian karyawan dengan metode Multifactor Evaluation Process (MFEP) di PT. Bina Sakato Jaya Kiliran Jao.

\section{Metodologi Penelitian}

Metodologi Penelitian Metode penelitian yang digunakan dalam menyusun penelitian adalah sebagai berikut [3]:

1. Metode pengumpulan data yang digunakan adalah:

a. Observasi Merupakan metode pengumpulan data dengan cara melakukan pengamatan terhadap objek secara langsung yaitu pada karyawan pt.x tersebut.

b. Wawancara (Interview) Yaitu wawancara langsung pada obyek penelitian yang dalam hal ini adalah karyawan. Kepustakaan Yaitu metode pengumpulan data dengan mempelajari buku-buku yang berkaitan dengan masalah yang sedang dihadapi dalam penelitian, misalnya buku pemrograman PHP, buku pengembangan sistem informasi, dan lain-lain. 
2. Jenis data yang dikumpulkan dalam penelitian ini adalah :

a. Data Primer Data primer adalah data yang diperoleh secara langsung dari sumbernya. Dalam hal ini memperoleh data karyawan pt. $\mathrm{x}$ yang dipesan.

b. Sekunder Data sekunder adalah data yang diperoleh secara tidak langsung yang berasal dari dokumentasi yang harus dipelajari dan dari sumber lain yang berupa majalah atau bukubuku misalnya buku pemrograman PHP, dan buku pengembangan sistem informasi. Literature Review Banyak penelitian yang sebelumnya yang sebelumnya dilakukan mengenai sistem pendukung keputusan.

\section{Ruang Lingkup Penelitian}

Agar penelitian ini lebih terarah dengan jelas dan sesuai dengan maasalah yang terjadi, maka penulis memberi batasan penelitian khususnya terhadap maslah sistem pendukung keputusan mutasi karyawan dengan metode MFEP di PT. Bina Sakato Jaya Kiliran Jao.

\section{LANDASAN TEORI}

\section{Pengertian sistem}

Sistem merupakan kumpulan dari elemen atau komponen atau subsistem [4]. Suatu sistem mempunyai maksud tertentu, ada yang menyebutkan maksud dari suatu sistem adalah untuk mencpai tujuan (goal) dan ada yang menyebutkan untuk mencapai suatu sasaran(objectives). Tujuan biasanya dihubungkan dengan ruang lingkup yang lebih luas sementara sasaran memiliki ruang lingkup yang lebih sempit.

\section{Pengertian sistem Pendukung Keputusan.}

Sistem pendukung keputusan merupakan sistem pemodelan dan pemanipulasian data yang digunakan untuk membantu mengambil keputusan dalam situasi yang semi terstruktur dan yang tidak terstruktur. Pemanfaatan sistem pendukung keputusan dalam penentuan penerima beasiswa termasuk dalam masalah semi terstruktur [5].

Untuk membantu pengambil keputusan dalam memutuskan suatu masalah manajerial, maka dibutuhkan kualitas informasi yang Relevan (informasi tersebut terkait dengan keputusan yang akan diambil), akurat (kecocokan antara informasi dengan kejadiankejadian yang diwakili), lengkap (seberapa jauh informasi menyertakan kejadian-kejadian yang berhubungan), tepat waktu (Informasi sesuai waktu kejadiannya), dapat dipahami dan dapat dibandingkan antara dua obyek yang mirip.

\section{Komponen Pengmbilan Keputusan}

Suatu SPK memiliki tiga subsistem utama, yaitu:[6]

1. Manajemen Basis Data (database)

Subsistem data merupakan komponen SPK penyedia data bagi sistem. Data ini disimpan

2. dalam database yang diorganisasikan oleh DBMS (Data Base Manajemen System).

Subsistem Manajemen Basis Model (model base)

Model adalah peniruan dari alam nyata. Model ini dikelola oleh model base.

3. Subsistem Manajemen Penyelenggara Dialog (user

system interface)

Melalui sistem dialog inilah siste diimplementasikan sehingga pengguna atau pemakai dapat berkomunikasi dengan sistem yang dirancang.

\section{Metode Multifactor Evaluation Process (MFEP)}

Dalam metode MFEP ini pengambilan keputusan dilakukan dengan memberikan pertimbangan subyektif dan instutif terhadap faktor yang dianggap penting. Pertimbanganpertimbangan tersebut berupa pemberian bobot atas multifaktor yang terlibat dan dianggap penting tersebut. Langkah dalam metode MFEP ini yang pertama adalah menentukan faktor-faktor yang dianggap penting, yang selanjutnya membandingkan faktor-faktor tersebut sehingga diperoleh ukuran faktor berdasarkan kepentingannya dari yang terpenting, kedua terpenting dan seterusnya.

Multifactor Evaluation Process (MFEP) merupakan model pengambilan keputusan yang menggunakan pendekaan kolektif dari proses pengambilan keputusannya. Model Multifactor Evaluation Process (MFEP) [7].

MFEP merupakan masalah- masalah yang kompleks dimana aspek atau faktor yang diambil cukup banyak. Oleh karena itu untuk 
mempermudah dalam penggunaan model MFEP ini, akan dibuat suatu sistem penunjang keputusan yang diterapkan dalam suatu sistem informasi dalam bentuk aplikasi komputer dengan model Multifactor Evaluation Process (MFEP).

Proses pemilihan alternatif terbaik menggunakan "weighting system", dimana metode tersebut merupakan metode kuantitatif, disebut sebagai metode "Multifactor Evaluation Process" (MFEP).

\section{Sekilas Microsoft Visual Basic.Net}

Menurut Frazelli [8], "Visual basic adalah salah satu bahasa pemrograman berbasis desktop yang dikeluarkan (diproduksi) oleh perusahaan perangkat lunak computer terbesar yaitu Microsoft. Menurut Marlon Leong (2010:3), "Visual basic adalah bahasa pemrograman yang lebih sederhana dibanding bahasa pemrograman yang lain karena visual basic membebaskan pemrogram dari penulisan perintah atau instruksi yang komplekssehingga langkah pemrograman menjadi jauh lebih sederhana".

\section{Sekilas Tentang Mysql}

MySQL adalah sebuah sistem manajemen database relasi (Relational Database Management System) yang bersifat "terbuka" (open source). Terbuka maksudnya adalah MySQL dapat didownload oleh siapa saja. [9]

\section{ANALISA DAN HASIL PENGUJIAN SISTEM}

\section{Analisis Sistem}

Sistem penunjang keputusan yang dibuat adalah make decisions yaitu jenis penunjang keputusan yang memberikan keputusan menungu legitiminasi dari pihak menejemen untuk dilaksanakan.aplikasi ini menggunakan pendekatan top down yang merupakan cirri dari perancangan struktur.aplikasi ini melibatkan kemampuan untuk melihat data internal dan data eksternal berupa kreteria penilaian.sehinga keputusan dapat mendiskusikan kreteria dan alternative yang beragam. [10]

\section{Analisis Algoritma Multifaktor Evaluasi Proses}

Proses pemilihan alternatif terbaik menggunakan 'weighting system', dimana metode tersebut merupakan metode kuantitatif, disebut sebagai metode 'Multifactor Evaluation Process' (MFEP). Dalam pengambilan keputusan multifaktor, pengambilan keputusan secara subyektif dan intuitif menimbang berbagai faktor yang mempunyai pengaruh penting terhadap alternatif pilihan mereka.per pertama seluruh kriteria yang menjadi faktor penting dalam melakukan pertimbangan diberikan pembobotan (weighting) yang sesuai dan dilakukan terhadap alternatif-alternatif yang akan dipilih, dan kemudian dapat dievaluasi berkaitan dengan faktor- faktor pertimbangan tersebut.

\section{Hierarchy Input Procces dan Output (HIPO)}

HIPO merupakan alat dokumentasi program yang berdasarkan fungsinya untuk meningkatkan efesiensi usaha pengolahan data program. Dokumen ini dilaksanakan dengan mempercepat lokasi dalam kode pada fungsi program yang akan dimodifikasi. Atau dapat dikatakan bahwa HIPO dikembangkan agar tersedia suatu teknik untuk mendokumentasikan fungsi program. Untuk lebih jelas dapat dilihat pada gambar 3.1.

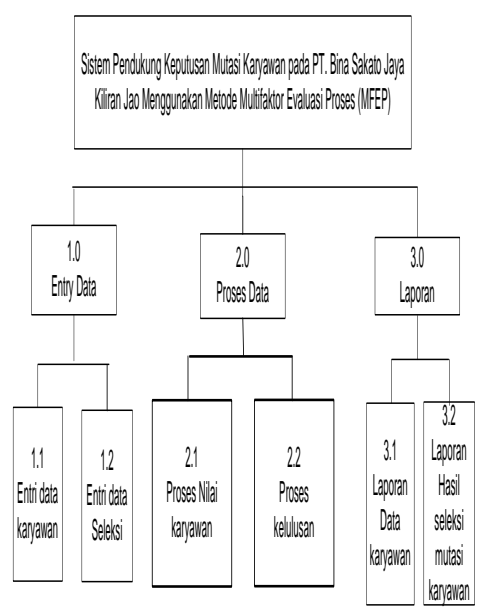

Gambar 3.1 HIPO

\section{Entity Relational Diagram (ERD)}

Dalam diagram menyatakan hubungan antara entity-entity yang terdapat dalam suatu database disebut entity Relational Diagram (ERD). Pada sistem pengambilan keputusan seleksi Mutasi karyawan. Untuk lebih jelasnya dapat dilihat pada gambar 3.2. :

\begin{tabular}{lr}
\hline 12 & Fakultas Teknik UMSB \\
& ISSN 2599-2081 \\
& EISSN 2599-2090
\end{tabular}




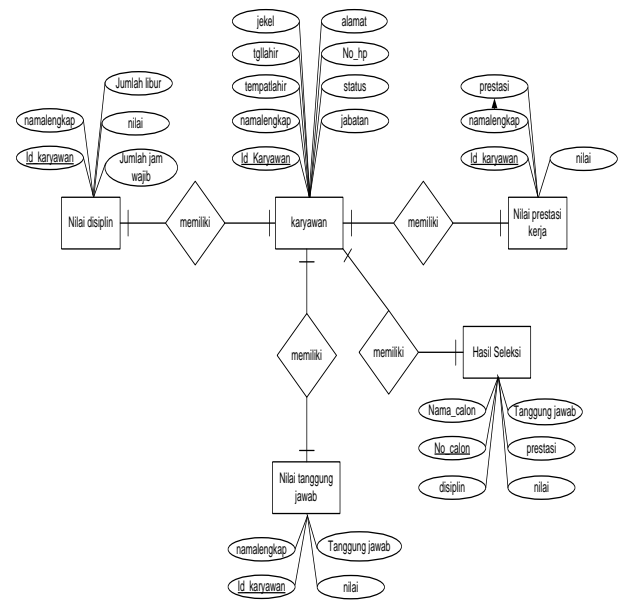

Gambar 3.2 Entity Relationship Diagram

\section{IMPLEMENTASI SISTEM}

Sistem Penunjang Keputusan Mutasi Karyawan pada PT. Bina Sakato Jaya Kiliran Jao merupakan sistem aplikasi yang dapat digunakan oleh staf pelayanan dalam melakukan rekapitulasi data. Menu utama dari sebuah sistem merupakan halaman yang paling pertama tampil ketika sistem itu dijalankan.

\section{Form Input}

\section{a. Menu Utama}

Menu utama pada seleksi mutasi karyawan menu entri data calon, menu laporan data calon, dan menu keluar. Fungsi menu entri data calon yaitu menginputkan data-data calon mutasi baru ke dalam database. Pada menu laporan proses seleksi data terdapat form entry data karyawan dan entry panilaian. Pada form laporan yaitu laporan data karyawan dan laporan hasil tes akhir. Untuk lebih jelasnya dapat dilihat pada gambar 3.3.

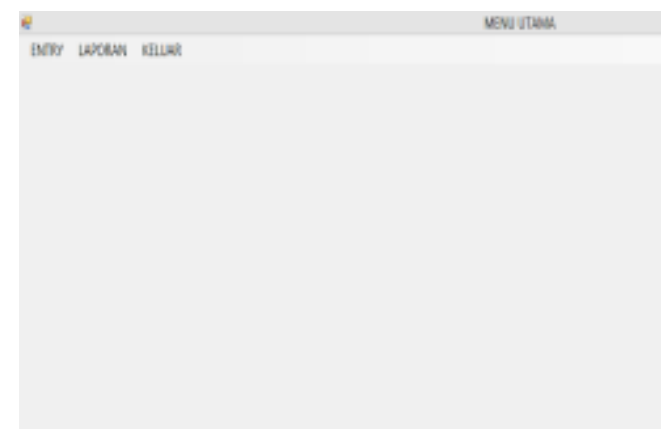

Gambar 3.3 Menu Utama Sistem Penunjang Keputusan Seleksi Mutasi Karyawan PT. bina sakato jaya kiliran jao

\section{b. Entri Data Karyawan}

Form entri data karyawan berfungsi untuk menambah, menyimpan, dari data karyawan. Adapun bentuk data-data yang diinputkan dapat dilihat pada gambar 3.4.

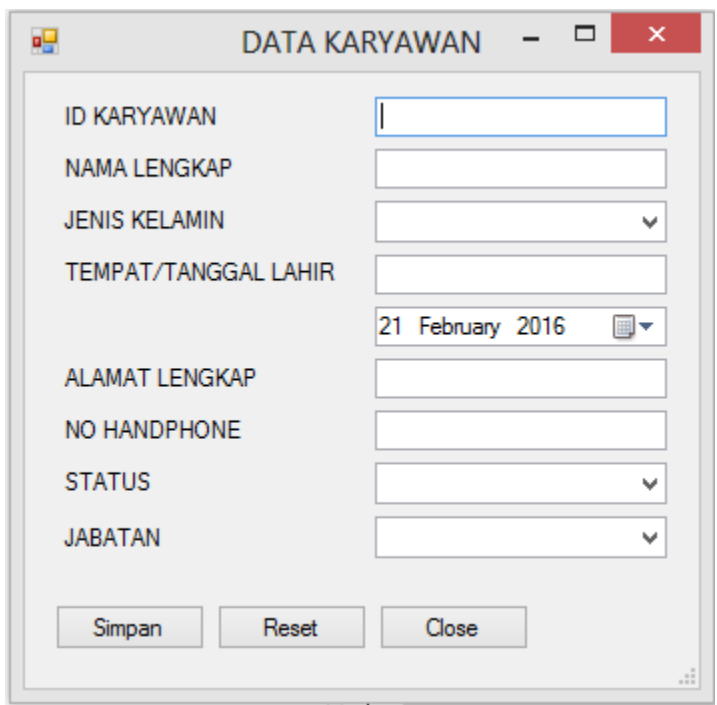

Gambar 3.4 Form Entri Data Karyawan

\section{c. Input Data Seleksi}

Form input data seleksi berfungsi untuk menseleksi hasil karyawan yang akan dimutasi. Adapun bentuk datadata yang diinputkan adalah sebagai berikut:

\section{Form Input data nilai Seleksi Disiplin}

Form input data nilai seleksi untuk nilai disiplin karyawan yang ikut seleksi mutasi. Adapun bentuk form input data-data dapat dilihat pada Gambar 3.5.

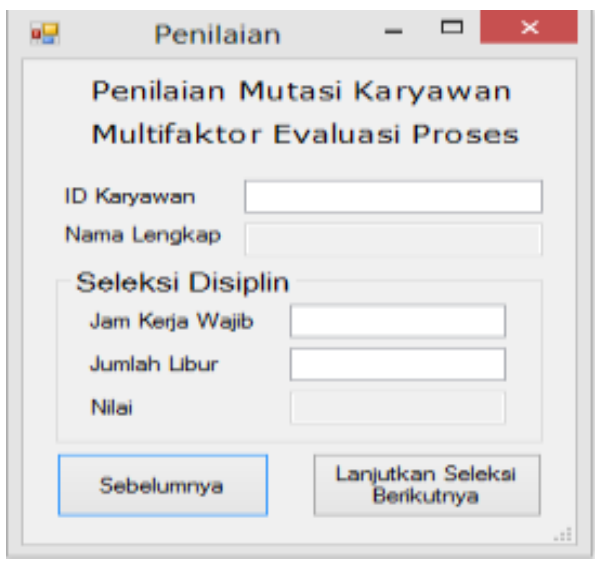

Gambar 3.5 Form Input Data Seleksi Disiplin 
1. Seleksi Tanggung Jawab

Form input data nilai seleksi untuk nilai disiplin karyawan yang ikut seleksi mutasi. Adapun bentuk form input data-data dapat dilihat pada Gambar 3.6.

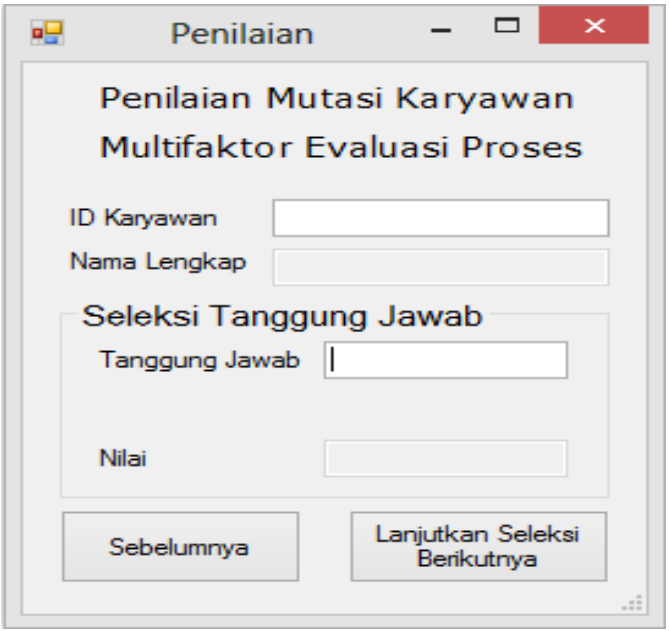

Gambar 3.6 Form Input Data Seleksi

Tanggung jawab

2. Form input data Seleksi Prestasi

Form input data nilai seleksi untuk nilai prestasi karyawan yang ikut seleksi mutasi. Adapun bentuk form input data-data dapat dilihat pada Gambar 3.7

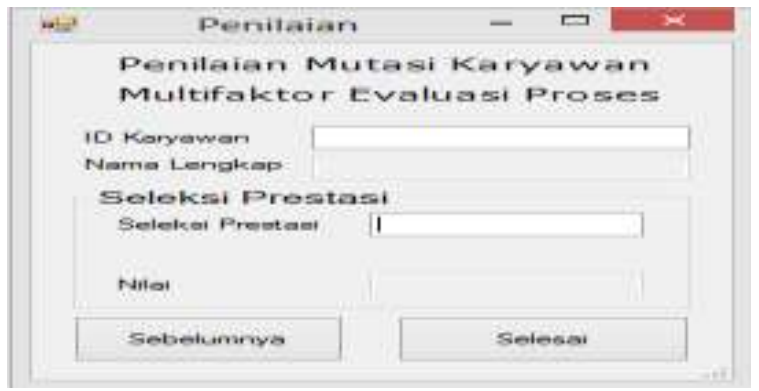

Gambar 3.7 Form Input Data Seleksi Prestasi

\section{Form Output}

Form output merupakan jembatan untuk menghasilkan dokumen yang ingin dicetak. Form output memberikan laporan data karyawan dan hasil akhir seleksi, adapun bentuk laporan berikut ini:

\section{Laporan Data Karyawan}

Laporan data karyawan berfungsi untuk menampilkan data laporan data karyawan siap cetak. Adapun bentuk laporan data calon dapat dilihat pada gambar 3.8.

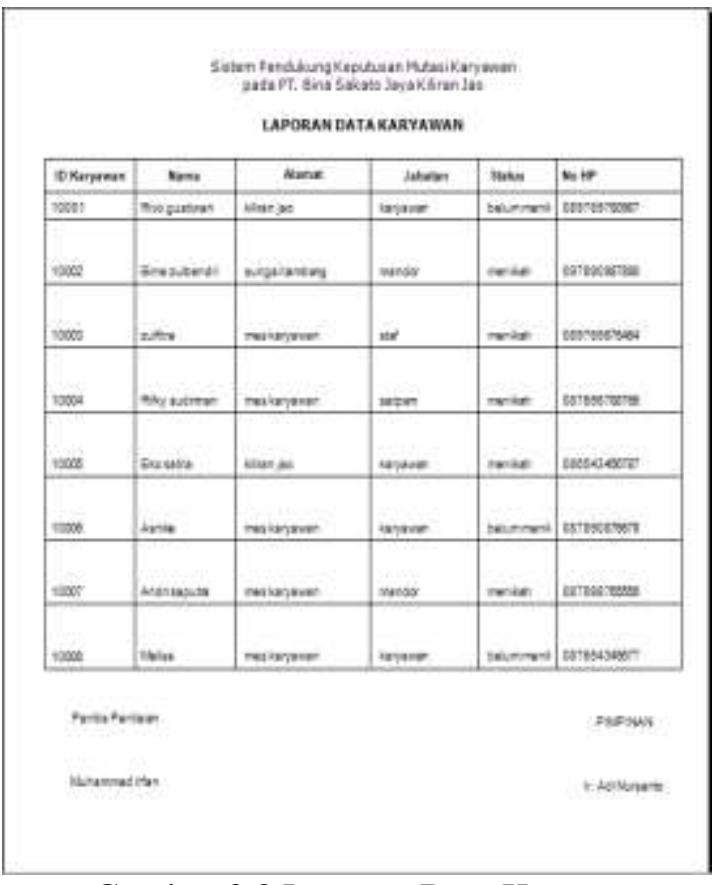

Gambar 3.8 Laporan Data Karyawan

\section{Laporan Data Mutasi}

Laporan data mutasi berfungsi untuk menampilkan data laporan data hasil penilaian mutasi siap cetak. Adapun bentuk laporan dapat dilihat pada gambar 3.9.

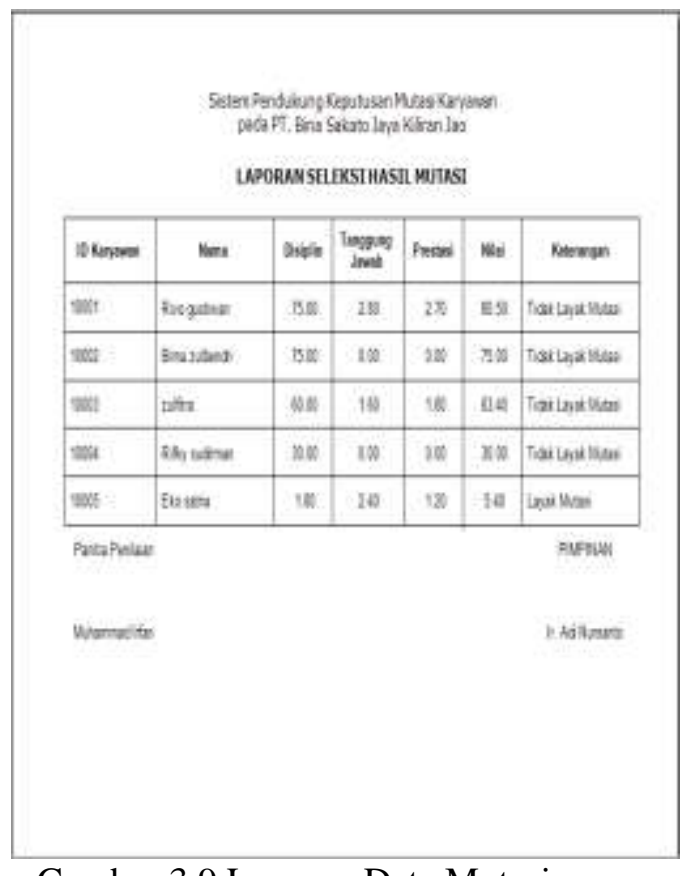

Gambar 3.9 Laporan Data Mutasi

$\begin{array}{lr}\text { Fakultas Teknik UMSB } & \text { ISSN 2599-2081 } \\ \text { EISSN 2599-2090 }\end{array}$




\section{SIMPULAN}

Dari hasil kajian terhadap perancangan Sistem Penunjang Keputusan Seleksi Mutasi Karyawan menggunakan Metode Multifactor Evaluation Process dapat ditarik kesimpulan bahwa :

1. Dengan adanya sistem ini dapat membantu pihak panitia dalam menentukn karyawan yang akan dimutasi.

2. Dengan adanya Sistem Penunjang Keputusan Seleksi Mutasi Karyawan yang diajukan telah membantu pimpinan dalam menerima informasi data karyawa yang dimutasi dengan cepat dan tepat.

3. Informasi yang dibutuhkan dapat dilihat setiap saat dengan mudah dan kapanpun jika dibutuhkan serta penyimpanan datanya terjamin aman. Serta Output atau laporan-laporan yang dihasilkan pada sistem ini lebih jelas dan terinci.

\section{UCAPAN TERIMAKASIH}

Ucapan terima kasih kepada lembaga LPPM STMIK Indonesia Padang dan juga kepada pimpinan PT. Bina Sakato Jaya Kiliran Jao yang telah membantu dalam pelaksanaan penelitian ini yang telah membantu baik dalam bentuk moril maupun material..

\section{DAFTAR PUSTAKA}

[1] M. Program, S. Ilmu, F. I. Sosial, I. Politik, and U. Mulawarman, "JURNAL PELAKSANAAN MUTASI PEGAWAI NEGERI SIPIL DI BADAN KEPEGAWAIAN DAERAH DARI KABUPATEN KUTAI BARAT KE KABUPATEN MAHAKAM ULU," eJournal Ilmu Pemerintahan, 22014 3080 - 3091 ISSN 0000-0000, ejournal.ip.fisip.unmul.ac.id, vol. 2, no. 3, pp. 3080-3091, 2014.

[2] P. R. Afrizal, M. Al Musadieq, I. Ruhana, F. I. Administrasi, and U. Brawijaya, "Pengaruh konflik kerja dan stres kerja terhadap kepuasan kerja," J. Adm. Bisnis (JAB)| Vol. 8 No. 1 Februari 2014| Adm., vol. 8, no. 1, 2014.

[3] D. Supriyanti, "APLIKASI SISTEM ORDER ONLINE BERBASIS MOBILE ANDROID PADA OUTLET PIZZA
HUT DELIVERY," Semin. Nas. Teknol. Inf. dan Multimed. 2017 STMIK AMIKOM Yogyakarta, 4 Februari 2017, pp. 1-6, 2017.

[4] J. O. Sembiring, U. Santo, T. Sumatera, J. Setiabudi, and N. F. Tanjungsari, "Sistem Informasi Penjualan Barang dan Jasa pada Studio Photo Topaz Hexagon Medan Berbasis Web," ejournal.ust.ac.id/index.php/Jurnal_Mean s/ p-ISSN, vol. 2, no. 2, pp. 76-83, 2017.

[5] C. B. Andrianto and $\mathrm{H}$. Al Fatta, "ANALISIS SISTEM PENDUKUNG KEPUTUSAN PENERIMA BEASISWA DI SMP MUHAMMADIYAH 2 KALASAN," Vol. XII Nomor 34 Maret 2017 - J. Teknol. Inf., vol. XII, pp. 46-60, 2017.

[6] C. R. Tampilang, P. Ii, and D. Dharmayanti, "Sistem Pendukung Keputusan Untuk Perencanaan Promosi dan Mutasi Jabatan di Hotel Patra Jasa Bandung," pp. 1-7.

[7] J. Prof, M. Y. No, and S. Kalimantan, "BERPRESTASI MENGGUNAKAN METODE MULTIFACTOR," J. Sist. Informasi, Vol. 5, Nomor 2, Sept. 2014, hlm. 95-101 Rumusan, vol. 5, pp. 95-101, 2014.

[8] C. Utara and B. V. B. Net, "KOMPUTERISASI AKUNTANSI SIMPAN PINJAM DAN KREDIT BARANG PADA KOPERASI GURU DAN KARYAWAN SMA NEGERI 2," J. Interkom Vol.12 No. 4 - Januari 2018, vol. 12 , no. 4, pp. 14-23.

[9] J. S. Informasi, U. I. Indragiri, J. S. Informasi, and U. I. Indragiri, "SATIN Sains dan Teknologi Informasi Rancang Bangun Aplikasi Online Global-net Elektronik Berbasis Web," SATIN - Sains dan Teknol. Informasi, Vol. 4, No. 1, Juni 2018, vol. 4, no. 1, 2018.

[10] N. Aminudin, I. Ayu, P. Sari, and R. No, "SISTEM PENDUKUNG KEPUTUSAN ( DSS ) 